\title{
Factors that promote the adoption of a high-density and mixed-use development: examining a potential urban village based on urban design principles
}

\author{
S. T. F. Poon \\ Taylor's University, Malaysia
}

\begin{abstract}
This paper outlines the findings of qualitative research undertaken to investigate the possibility of adopting urban village design principles in transforming the neighbourhood of Petaling Jaya in Malaysia. The purpose of this study was to investigate perceptions towards the potential of high-density cities and townships that face socioeconomic, environmental and other challenges, and how adopting the concept of an urban village could improve the quality of residents' lives, encourage pedestrian walkability, increase social dynamics and local connectivity through communication channels, develop mixed use zoning for infrastructures, as well as improve traffic problems on increasingly hectic roads. Upon critical interpretation and in-depth analysis of the urbanisation context in Petaling Jaya, this study reveals that the potential initiatives, mechanisms and solutions for sustainable and holistic urban development may improve life quality for certain stakeholders, but the benefits are not necessarily shared by others in the community. Findings in this paper indicate that bias and interests are represented by dominant-collective factions, hence, more careful research will be required to consider socioeconomic benefits and impacts of mixed use zoning before adopting specific elements to transform Petaling Jaya into a prospective urban village. Understanding local communities' wishes and desires on improving certain aspects of liveability is crucial before implementing any concept of living without losing its image of urbanisation and progress.
\end{abstract}

Keywords: urban village, design, mixed use, quality of life, urbanisation. 


\section{Introduction}

In the two decades since the publication of Our Common Future by the United Nations World Commission on Environment and Development [1], cities around the world have experienced rapid growth and massive rural migration phenomena leading to unsustainable population increases and unprecedented patterns of consumption and production that have transformed spatial and social landscapes. Inferring from studies of political histories, it was observed by Cockcroft in [2, p. 139]) that territorial and resource exploitation for industrial and economic activities are correlated to growth in modern cities. With housing and industry comprising the major land use of urban areas, larger population centres with manmade environments invite inevitable problems, and simultaneously impact on smaller townships and suburbs located in outlying neighbourhoods.

A counter movement to modernism has been seen in the rise of urban villages since 1990s, characterised by mixed uses of gazetted public space, pedestrianisation and medium-density housing, efficient traffic solutions. The provision of communal lifestyles and recreational choices which encourage social interaction while mitigating environmental consequences, are integrated towards improving the quality of life in such self-contained city neighbourhoods. This concept of modernity, known as urban village, have been studied for its geographic, cultural and socioeconomic significance by spatial theorists such as Benko and Strohmayer [3] and urban critic Roberta B. Gratz [4, p. 25]. The argument is that urban villages in rapidly-growing cities provide town councils and municipal authorities with the opportunity to create stakeholder awareness of their shared identity, ownership and responsibilities to protect, sustain, endow, and in some cases, restore the balance of social structures, cultural networks and economic functions that have brought neighbourhoods their modernity and prosperity.

For this paper, it is hypothesised that transforming Petaling Jaya (PJ) into an urban village would enable urban planners to adopt certain characteristics of modern cultural landscapes. A framework of questions was produced in researching the model of an urban village, based on quality of life, walkability, connectivity, develop mixed use zoning and traffic improvement. The objective of this study is consider the validity of these factors for the transformation of Petaling Jaya into an urban village that adopts specific physical elements such as traditional neighbourhood linkages and mixed use sustainable community development.

\section{Literature review}

Costs (economic) and social enhancement strategies are two critical aspects of national urban development and town planning studies. Researchers and experts in urban design and spatial planning - particularly for developing countries ought to place at the foundation of all initiatives, people and social benefits, as well as environmental impacts that macroeconomic policies and provisional shifts are designed to develop and expand. The profit aspect, while essential to buffer 
income and raise employment prospects, should be complementary instead of contradictory [1:204].

The key components of urban lifestyles - energy consumption and sustainability - inevitably arises in recent literature on urban planning contexts [1, pp. 41-58, 4, pp. 71-94]. But whose decisions are being adopted and considered in such scenarios where the needs of vibrant city lifestyles do not upset the need for environmental balance? Hui Kong et al. [5] researched the social and economic implications of high-density Asian cities experiencing spiralling growth, and found that in Changping, Beijing, a bottom-up collective-dominant development model is more effective that top-down, centrally-controlled models, to ensure social inclusion and participation of stakeholders before the implementation of mixed use areas. This argument precedes the rationale that although city councils are responsible for effective functioning related to health, waste management, infrastructural maintenance and regulatory controls, urban planners, architects and designers are most representative of the collectivedominant faction, tasked with promoting and integrating energy-efficient innovations (e.g. renewable energy) into spatial planning [3, 4, p. 5] that affect individual and community wellbeing [1, pp. 141-172]. Sustainability field studies suggest that balance is crucial for long-range environmental engineering of human society where urban systems planning, similar to ecosystem principles of natural algorithms, can be integrated with without destroying ecological equilibrium [6]. On the global scale, the increased consumption of non-renewable energy sources for transportation, cooling and electricity generation has added pressure on the development of better air-quality measures for optimal building designs under specific climate and humidity conditions [7, 8]. In Malaysia, innovative urban planning models incur designing resilient products and projects that apply technologies using renewable resources and optimised structural designs [9, pp. 14-18].

Various factors of urban liveability have been highlighted and evaluated from a range of research and applied perspectives such as Borden et al. [10] and Gratz [4, p. 25]. Cultural geographer Iain Borden [10, p. 115] explains that local metaphors, regional mythologies and iconographic elements are useful to pinpoint the literal and hidden meanings embedded into landscapes, and when applied to high-density urban locations, these cultural contexts provide reflexive understanding to locals and visitors; giving a simple way to express when prompted, So what do you think/feel/know about (place)?

Jane Jacobs, observing inner city values and attributes of her neighbourhood Greenwich Village in 1960s New York, found that the more intricate the relationships of people in urban spaces, the more diverse the needs and circumstances that enable economic and social functioning, and yet, the less visible would these networks be to outsiders who perceive "seeming chaos and jumble" (Gratz, cited in [4, p. 27]; cited in [5, p. 94]).

Benko and Strohmayer [3, p. 44] state that consensus and collective participation is a constant concern for debates related to urban planning. The culture of communities is progressively established, transmitted and shared through relational strategies, such as discussion platforms, via mass media and the 
arts mediums, with media consumption based on geo-cultural and socioeconomic factors. With urban expansion, however, it is apparent that communication involves a spread of factors such as costs, distance and time, and technology help connect urban citizens and stakeholders to identify solutions, opportunities and realise community projects.

The urban village also embodies design principles that emphasise compact neighbourhoods, connectivity, social dynamism, sustainability and embrace of technology [4, pp. 2-24]. From a positive standpoint, it is a "smart" strategy as plays an elastic role in rapid urbanisation (Hall in [4, pp. 48-94]) - by supplying affordable, temporal, well-planned housing for different income segments; assisting the government's broader initiatives to regenerate less-thriving inner city areas; providing employment, recreational and community facilities, and a range of lifestyle amenities, services and leisure located in mixed use infrastructures [4, p. 85], as well as enabling residents to earn their living from serving locals and thus sustain the economic balance of the region in tandem with the state's holistic urban expansion programmes.

After examining scholarly perspectives, this research aims to produce a study more relevant to Malaysia's experience of neighbourhood development and sociocultural place-making issues. Firstly, how far can the urban village design principles balance other emerging issues in Malaysia's own experience of urbanisation? Next, how should the ideal practices of an urban village be appropriated, after considering its advantages and disadvantages? To initiate discussion for these key themes, the next section provides background details of Petaling Jaya.

\subsection{Background of the study}

Urban, as identified by the Department of Statistics Malaysia [11], infer the "gazetted, adjoining built-up areas with a population of 10,000 or more ... (of whom) at least $60 \%$ are engaged in non-agricultural activities". Petaling Jaya, starting as a satellite town of Kuala Lumpur in the 1950s [20], was originally planned to accommodate 70,000 people through housing and employment opportunities. From being a township, it has grown into a municipality, and since attaining city status in 2006 , its population has crept up to nearly 620,000 and approximate 218,000 property dwellings, representing future challenges to expansion [12].

Case studies on good community practices in urban development commissioned by the Asian Development Bank show that the introduction of United Nations' Local Agenda 21 initiative to guide localised action plans for sustainable high-density development, has to balance economic, community and environmental interests with collective objectives before implementation, ensuring local stakeholders' engagement for consultation, feedback and reviews via awareness strategies such as training, exhibitions and briefings to build a "comfortable, harmonious and healthy city within (its) environment [13, pp. 229230]. 


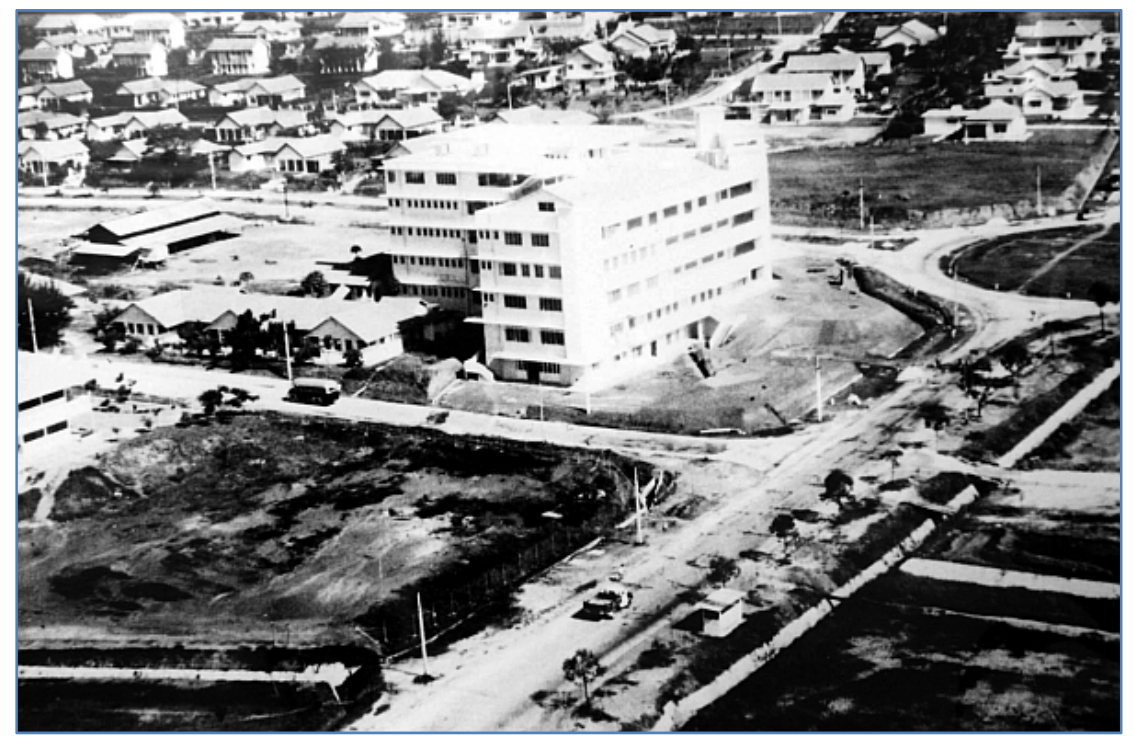

Figure 1: First hospital in Petaling Jaya: Hospital Assunta, founded in 1954 [20].

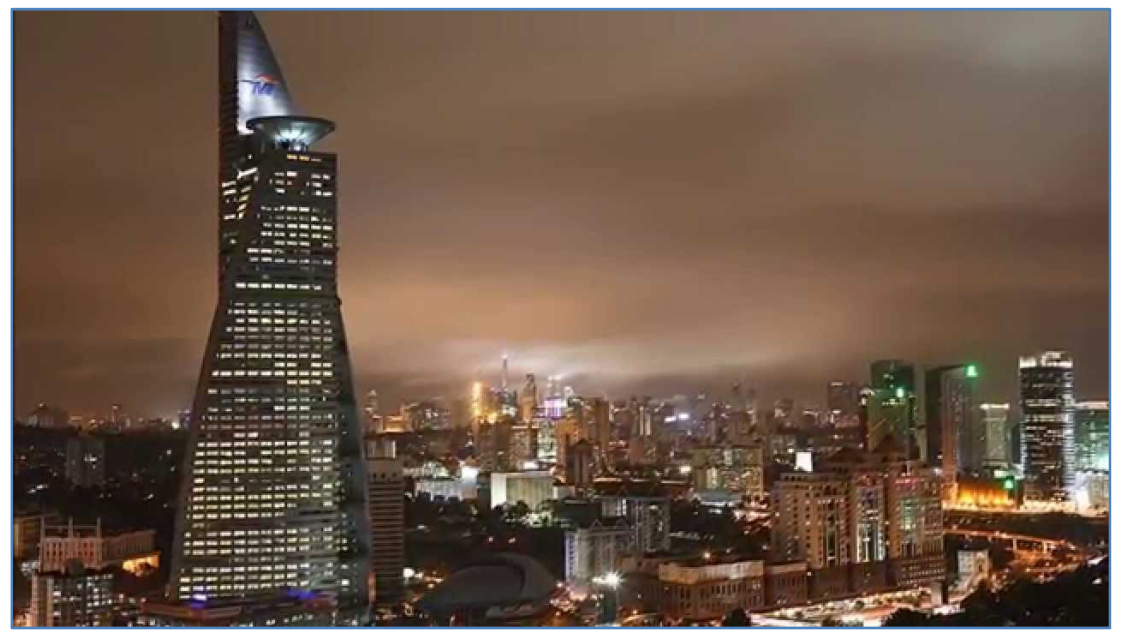

Figure 2: $\quad$ Petaling Jaya Skyline [21].

Considering the current scenario, whereby housing densities in Petaling Jaya have been previously noted to reach unprecedented heights in the past decades, newer expansion schemes suggest that similar number could be accommodated on less land areas [21]. In discussing local residents' feedback to Local Agenda 21, however, Petaling Jaya stakeholders with strong community interests show how deeply they value their natural areas, and are rightly concerned that building homes 
near to rivers, ravines, and other environmental features would be detrimental to holistic, incremental development of cities [13, pp. 231-232].

\section{Methods of research approach}

To further discuss the earlier hypothesis, a qualitative framework for analysis was developed as the research methodology for this paper. Semi-structured interviews were conducted with six participants to understand the current perceptions of Petaling Jaya liveability conditions, through qualitative descriptions of the characteristics of suburban and urban development in the past ten years. In order to focus on the potential of adopting the urban village concept for Malaysia's quality of life improvement, local participants were selected on the basis of being active in urban development programmes, or have had substantial immersive experience designing urban environments such as housing and commercial properties, making them reliable sources of information about the characteristics of various urban designs [14, p. 177].

Participants were approached via face-to-face session. The interviews were conducted in six sessions, with each session approximately one hour thirty minutes. Data collection took six weeks. In-depth interview is the instrument to get the story behind the practitioners' experiences. The six participants are two Architectural Designers (AD1 and AD2), two are Landscape Architects (LA1 and LA2) and two are Town Planners (TP1 and TP2). The practitioners responded independently using a set of questionnaires based on face-to-face session. Without being overly rigid and prescriptive, the replies were analysed for commonalities, and each practitioner's responses was synthesised.

Using the urban village landscape elements described, an analysis of responses is provided in the discussion of qualitative findings that follows.

\section{Discussion of findings}

After data was gathered, a summary looking at the findings produced a distinct concurrence among respondents that urban growth was a relatively recent cultural phenomenon for Malaysia stretching back no more than twenty years.

Participants characterised the present residential neighbourhoods that now dot urbanised areas throughout Malaysia's capital cities as "high-density", "automobile dependent", "unstable employment", "imbalance in housing", "culturally-dispersed" and "segregated", which implies a predominant polarisation by ethnicity, economic and social classes in Malaysian society. Their attribution of cultural landscapes for the city concurs with Pepinsky's [15] findings that in spite of Malaysia's medium- to high-levels of ethno-geographic crosscutting, such as that found in Petaling Jaya, there is persistent fragmentation of population groups based on socioeconomic profiling.

As field professionals, participants demonstrated sufficient conceptual understanding about urban village, with TP1 describing it thus:

When you plan things, the most important thing is the aim of your planning or your design; the most important thing is (that) whatever you do in terms of the 
environment, social, economy ... good spatial planning is to make the place prosper.

TP2 acknowledged that individual experiences of society that urban planning must embrace:

Prosperity of cities - well, here, we think it must of course be about the economy, but (there is much more) we can measure. Social progress, I think, comes from ensuring fair and adequate provision of governmental and business amenities, schools, universities, clinics and hospitals, and our right to embrace the faith we wish. All these must be reflected in land use planning. Malaysian state laws give provisions for proper zoning of mosques, temples, churches and significant buildings ... so I think if (you want to include this aspect as) progress, it is one of the most important and basic things that an urban planner should consider.

\subsection{Quality of life}

Urban quality of life principles, according to participants, must be holistically approached. "Taken together, these principles add up to a life worth living, and create places that enrich, uplift, and inspire the human spirit". One of the town planners described the way many individuals veer off-track and have a wrong conception of the notion of quality-of-life:

(Society in general) always talk about materialist, lifestyle trends. (For instance) a successful accountant, living in a high-rise condominium, plays golf with successful professionals, (earning) a level of wealth that supports regular dining at five-star hotels and vacations at five-star resorts. Of course, that kind of living can satisfy desires and (give proof of) social status. But no, the kind of urban planning we are talking about here, is to create spaces for those same people to walk, drink, eat, live, work and build families - right there, not at a distance, not in unfamiliar surroundings.

\subsection{Walkability}

Walkability is another issue that defines the urban village concept. Participants say things should ideally be within a 10-minute walk from the home or workplace; streets are mostly pedestrian-friendly - and in special cases - free of cars. TP1 argues that pedestrianisation, while beneficial, must derive efficient linkages to other systems and services, implying the importance of the culture of change management and long-range policy planning:

Because the urban village scale is small, you can walk, no problem. But you have to start walking from somewhere, like a car park. So there is a need for car parks, public transportation hubs, and decent public amenities, such as toilets, all designed to raise citizens' living standards. Walking in such a township gives you a sense of pride ... it is good for health, but just as important, we have to ask, are there practical conveniences available such as enough car parks? Can these changes be progressive as the city's boundaries or its suburbs keep on enlarging, and additional population compounds the ecological problems and costs even more? 


\subsection{Mixed use zoning}

The urban village concept entails a walking-friendly, compact (not necessarily coherent) fusion of land areas and functions [Lynch, cited in 5:94]. As described by LA1, this presents a place where "a mix of shops, offices, services, recreational activities, apartments and terraced homes (are found) - all within neighbourhoods, within blocks and within buildings, suitable for a diversity of different ages, income levels, cultures and lifestyles". The mixed use principle of permitting access to a full range of infrastructural and lifestyle amenities had been proposed as a symbolic incentive to build local social interactions and reduce fuel consumption for transportation and travel $[16,17]$.

LA2 concurs, but thinks it should be "really user-oriented ... residential areas must be within proximity of shopping, neighbourhood stores and commercial hubs, not industrial hubs or factories; homes must be situated away from transmission lines and power generators". AD2 described the usage of spaces as fundamentally a behavioural aspect of residents' lifestyles:

When you shop, you look for goods and services, yes, but also-you seek some kind of 'connectivity' with the shops, and a pattern of belonging between shops. You will feel the value of your time more when the whole experience is complementary, meaning the range, variety and nature of commerce complement each other. Second, you want experiences that are supplementary: meaning the outlets, while competing for customers, also somehow co-exist and support each other, to adding value to the process of consumer socialisation in general.

TP2 comments on the function of universal semiotics required in spatial design, in terms of commercial and retail imagery that makes more sense to the public:

In terms of design, this synergy means some homogenous features of design is required to identify a sector of business, e.g. signboards of restaurants or telecommunications outlets; but let colour, depth, symbolic meaning and textures match the concept of the individual store or shop.

\subsection{Communication and connectivity}

Studies shown that digital transition for Malaysia occurred in tandem with its demographic expansion, along with other media outlets such as newspaper, television and radio [18], and these findings correlate with scholarly research about the importance of connectivity to build citizenry and social cohesion of local communities [19]. As argued by Yuen et al. (in [13, pp. 231-232]), the transparency, visibility, responsiveness and equitable participation of Petaling Jaya's council administrators in the last decade is a positive outcome of the multisectoral communication initiatives to gather input from residents' associations, urban planning experts, institutions and NGOs. Such linkages are also greatly facilitated by the high penetration and usage of Internet, broadband and mobile in homes, offices and other public, connected spaces.

Community engagement was described variously as "community involvement", "public input about desires", "activism" or "stakeholder participation". These terms signal participants' acknowledgement that social 
inclusion via two-way communication methods is crucial, although spatial factors are physical barriers for community integration in dense urban areas [5, p. 100]. The town planner:

I think citizens' desires come first to mind (when urban planning is discussed) and PJfolks have certainly been making their desires known in the last decade or so, telling the city council what their needs are, during face-to-face meetings.

This accords with Neal [4], who suggests that constituencies are efficiently reached via direct communication modes such as town-hall meetings and public briefings. However, there are insufficient local studies to establish whether other channels such as radio, flyers and notices, and technologies such as neighbourhood Intranet, social media bulletins and platforms, for instance Twitter and Facebook - while enabling quick dissemination of information and events - are effective representation of the majority community's interests in localised issues.

AD2 further notes the various differences between top-down and bottom-up communication management between stakeholders in Petaling Jaya:

Well, the Internet facilitates citizens' input about better management of amenities ... (so) definitely, the views and sentiments of citizens and what their needs are, will create more open discussions. (Other residents) can read your comments and this will bring many perspectives and solutions to the table, but it is the council (being an authority with its own interests and agendas) that will ultimately finalise decisions.

\subsection{Improving traffic}

Urban planning must be in situ, and solutions implemented for localised, specific problems. Multi-level car parks, building a monorail system, campaigns encouraging cycling are ways to reduce dependence on vehicles and alleviate excessive traffic clogging suburban roads. Duany et al. [19, p. 149] note that airquality crisis arises from "laissez-faire construction", and urban planners must rightly be "suspicious" of any solution that implies more state-sanctioned roads, further compounding the suburban sprawl.

From interviewees' perspective, however, both public transportation and the added amount of vehicles plying Petaling Jaya main streets and residential roads have exacerbated the problem in the last two decades. Some suggestions were offered to improve liveability in facing the urban sprawl. The town planner thinks public participation needs to precede decisions on solving traffic issues as "distance, safety, physical and financial barriers, must be balanced at the planning, implementation and regulatory levels - let our voices represent our interests."

TP2 mentioned pedestrians and cyclists as important constituencies for urban landscapes:

PJ (City Council) in its town planning has specifically reached out to the bicycle community and recreationalists to identity space deficiencies, like the lack of cycling lanes. (This has) created more effective connections in the neighbourhood, such as planned green lungs and linear parks that make walking more inviting. 
TP1 notes:

(There is a) need to provide bridges that better accommodate pedestrians for a more seamless experience, while improving another important factor people's safety.

LA1 added:

As a seasoned cyclist, I feel on-going trail enhancements are crucial to help improve overall experience ... it will give us confidence to promote PJ among our outdoor-loving friends to join us for this activity, especially on weekends and public holidays.

AD1 sheds light on Petaling Jaya's still-active retired population who seek better facilities including access to age-appropriate recreational amenities. He suggests these facilities "meet the standards of communities that attract those populations", citing cities in Europe, United States and Australia known for pride and upkeep in their natural environments and outdoor amenities that enhance quality of life, while attracting desirable communities.

\section{Conclusions}

Some limitations of qualitative research approaches were considered. The participants may not have resided sufficiently long term in Petaling Jaya, hence their affiliation and issues familiarity are questioned. The sample could base their opinions on published media material or external views and thus not necessarily reflect the authenticity of sociocultural and economic realities of Petaling Jaya's established neighbourhoods in terms of experiencing actual changes in quality of life conditions. Based on critical interpretation of the contexts of urbanisation in Petaling Jaya, it is concluded that the potential initiatives, mechanisms and solutions for sustainable and holistic urban development may be strategic for certain stakeholders, but not entirely beneficial for the entire community. It could be gathered from the series of interviews that urban design principles are generally appropriated and perceived with personal bias where they serve particular interests, preferences and behaviours of the collective-dominant [5]. Expertise opinions, however objective, is not reflective of the collective community's voices when lesser-dominant stakeholders' views are not accounted for. As discussed in literature, the urban village model represents an opportunity to increase quality of life in densely-populated cities by creating pedestrian-friendly, connected, socially dynamic and sustainable environments. Hence, it is recommended that further examination of socioeconomic benefits and impacts of mixed use zoning could improve the feasibility of transforming Petaling Jaya into a prospective urban village.

It is suggested that larger survey research be conducted, based on cost and benefit analysis of traffic solutions such as building highways, fuel consumption and commuting time, and integration of local communities' needs through better communication management between top-down and bottom-up urban development models. The challenges, potential upsides and available options need to be thoroughly explored to understand perceptions of communities and 
create understanding on how active citizenry could thrive beyond present liveability issues through embracing the best practices of city living and social growth.

\section{References}

[1] United Nations (1987) Our Common Future: Report of the World Commission on Environment and Development (WCED) Oxford, UK: Oxford University Press.

[2] Henket, H.J. and Heynen, H., eds (2002) Back from Utopia: Challenge of the Modern Movement. Amsterdam: nai010 Publishers.

[3] Benko, G. and Strohmayer, U., eds. (2004) Human Geography: A History for the 21st-Century. London: Arnold/Oxford University Press.

[4] Neal, P. (2003) Urban Village and The Making of Communities. New York: Spon Press.

[5] Hui Kong, Sui, D.Z., Xin Tong, and Xun Wang (2015) Paths to mixed-used development: A case study of Southern Changping in Beijing, China. In Cities, 44: pp. 94-103. Amsterdam: Elsevier.

[6] Mitsch, W.J. and Jørgensen, S.E. (2003) Ecological Engineering and Ecosystem Restoration. 2nd ed. Hoboken, N.J.: John Wiley \& Sons.

[7] Santamouris, M. (2006) Environmental Design of Urban Buildings: An Integrated Approach. London: Earthscan.

[8] Markus, T.A. and Morris, E.N. (1980) Buildings, Climate and Energy. London: Pitman.

[9] Ruslan, H. (2016) Jurutera. (Bulletin of the Institution of Engineers Malaysia), August. Kuala Lumpur: The Institution of Engineers Malaysia.

[10] Borden, I., Miles, M. and Hall, T. (2004) The City Cultures Reader. 2nd ed. London: Routledge.

[11] Department of Statistics Malaysia (2015) Population and Housing Census. Retrieved from https://www.statistics.gov.my

[12] MBPJ, Majlis Bandaran Petaling Jaya [Petaling Jaya City Council] (2016) Background of Petaling Jaya. Retrieved from http://www.mbpj.gov.my $/ \mathrm{en} / \mathrm{mbpj} /$ profile/background

[13] Yuen, B., Ahmad, S. and Chin, S.H. (2006) Malaysia. In Urbanisation and Sustainability in Asia. B. Roberts and T. Kanaley (eds.) Asian Development Bank.

[14] Lindlof, T.R. and Taylor, B.C. (2011) Qualitative Communication Research Methods. Thousand Oaks, CA: Sage Publications Inc.

[15] Pepinsky, T.B. (2009) The 2008 Malaysian Elections: An End to Ethnic Politics? In Journal of East Asian Studies, 9(1): pp. 87-120.

[16] Pickus, J. and Gober, P. (1988) Urban Villages and Activity Patterns in Phoenix. Urban Geography, 9(1): pp. 85-97.

[17] Sharifah Mariam, M. A. (2010) Surviving Urban Renewal Program: Case Study of a Traditional Urban Village in Kuala Lumpur. Proceedings on National Resilience: Political Management and Policies in Malaysia 
(pp.277-314). Sintok, Kedah: Universiti Utara Malaysia. Available at: http://repo.uum.edu.my/3179/1/S15.pdf

[18] ZenithOptimedia (2015) Media Consumption Forecast 2015. A. Austin, J. Barnard and N. Hutcheon (authors). Retrieved from: www.zenith optimedia.com/wp.../11/NewMediaForecasts2015_Report.pdf

[19] Duany, A., Plater-Zyberk, E. and Speck, J. (2000) Suburban Nation: The Rise of Sprawl and the Decline of the American Dream. New York: Farrar, Straus and Giroux.

[20] Petaling Jaya: Then. (2012) First Hospital in Petaling Jaya: Hospital Assunta. September 20. Available at: http://historiesareheretostay.blogspot. my/2012/09/petaling-jaya-then.html

[21] World Cities (2015) Petaling Jaya Skyline. YouTube. February 05. Available at: https://www.youtube.com/watch?v=GWoEvM21OJ4 